International Journal of Medical Sciences ISSN 1449-1907 www.medsci.org 2004 1(1):50-61

(C)2004 Ivyspring International Publisher. All rights reserved

Research paper

Received: 2004.2.25

Accepted: 2004.3.17

Published:2004.3.20

\section{The primary prevention of birth defects: Multivitamins or folic acid?}

\section{Andrew E. Czeizel}

Foundation for the Community Control of Hereditary Diseases, 1148 Budapest, Bolgárkerék u. 3. Hungary

Periconceptional use of folic acid alone or in multivitamin supplements is effective for the primary prevention of neural-tube defects. The Hungarian randomized and two-cohort controlled trials showed that periconceptional multivitamin supplementation can reduce the occurrence of some other structural birth defects, i.e. congenital abnormalities. These findings were supported by many, but not all observational studies. Recently there have been two main debated questions. The first one is whether the use of folic acid alone or folic acidcontaining multivitamins is better. The second one is connected with the dilemma of whether high dose of folic acid (e.g. $5 \mathrm{mg}$ ) might be better than a daily multivitamin with $0.4-0.8 \mathrm{mg}$ of folic acid. Comparison of the pooled data of two Hungarian trials using a multivitamin containing $0.8 \mathrm{mg}$ folic acid and the data of the Hungarian Case-Control Surveillance of Congenital Abnormalities using high dose of folic acid seemed to be appropriate to answer these questions. Multivitamins containing 0.4 $0.8 \mathrm{mg}$ of folic acid were more effective for the reduction of neural-tube defects than high dose of folic acid. Both multivitamins and folic acid can prevent some part of congenital cardiovascular malformations. Only multivitamins were able to reduce the prevalence at birth of obstructive defects of urinary tract, limb deficiencies and congenital pyloric stenosis. However, folic acid was effective in preventing some part of rectal/anal stenosis/atresia, and high dose of folic acid had effect in preventing some orofacial clefts. The findings are consistent that periconceptional multivitamin and folic acid supplementation reduce the overall occurrence of congenital abnormalities in addition to the demonstrated effect on neural-tube defects.

Key words Folic acid, multivitamins, prevention, neural-tube defects, other congenital abnormalities

Andrew E. Czeizel, MD, PhD is the scientific director of Foundation for the Community Control of Hereditary Diseases, Budapest, and professor of Faculty of Genetics, Eötvös Loránd University of Sciences. He was the president of European Environmental Mutagen Society, one of founders of International Clearinghouse for Birth Defects Monitoring Systems, and director of the WHO Collaborating Centre for the Community Control of Hereditary Diseases. Dr. Czeizel serves on the editorial board of Congenital Anomalies and other editorial responsibilities. He is the first author of over 378 and coauthor of 39 published peer-reviewed English papers. He was presented award of US National Council on Folic Acid for Excellence in Research in the Field of Folic Acid and Birth Defects Prevention, 2002, and Peace Inter-Lyra Award, 2003. 


\section{Introduction}

Each year among 135 million new births in the world, about 3\% are affected with major structural birth defects, called congenital abnormalities (CAs). We can estimate more than 4 million each year or 11,376 daily of children born with CA. At present the total group of CAs is the major cause of infant mortality and disabilities among children in the industrialized countries. Therefore the prevention of CAs is an extremely important public health issue, since obviously we can secure the health in healthy born people.

There was a tremendous progress in the antenatal diagnosis of fetal defects due to ultrasound scanning, chromosomal and gene analyses, etc. However, parents - once informed that the fetus is severely affected by a defect - have to choose between two "evils", i.e. to have a malformed baby who will require long term medical care and have to deal with the social consequences of the defects, or to terminate the pregnancy. The great majority of prospective parents elect for termination of the pregnancy. Of course, this is a last resort rather than an optimal accomplishment. We have to do therefore our best to introduce the only one good solution, the primary prevention of CAs. No doubt that the primary prevention is better than the termination of pregnancy after the antenatal diagnosis of fetal defects (i.e. the so-called "secondary prevention", namely the prevention of birth of malformed fetuses). In addition, the cost and medical complications are much lower and there is no moral or guilty consequence due to the devastation of a human being.

In the early 1990s two randomized clinical trials have indicated the effectiveness of high dose of folic acid [1] or folic acid-containing multivitamin supplementation [2] during the periconceptional period in the primary prevention of recurrent [1] and first occurrence [2] of neural-tube defects (NTDs). The Hungarian randomized clinical trial has also demonstrated that the risk for CAs of cardiovascular system and urinary tract was reduced significantly, in addition limb reduction CAs and congenital pyloric stenosis showed a decreasing trend after the periconceptional multivitamin supplementation [35]. These findings have been confirmed by several observational studies [6] and by the second Hungarian intervention, the so-called two-cohort controlled trial [7]. The data of the large populationbased Atlanta Birth Defects Case-Control Study also showed a reduction in some CA groups beyond NTDs [8]. However, we were not able to confirm the previous finding of Tolarova [9] regarding the preventive effect of very high dose $(10 \mathrm{mg})$ of folic acid and other vitamins for recurrent cleft lip \pm palate in our intervention trials using a low dose of folic acid $(0.8 \mathrm{mg})$ containing multivitamin. In other studies on orofacial clefts, the preventive effectiveness of multivitamin supplementation varied considerable from 1.3 (i.e. $30 \%$ increased risk) [10] to 0.7 (i.e. $30 \%$ decreased risk).[11]

The primary prevention of CAs other than NTDs is extremely important because for example cardiovascular CAs account a larger fragment of infant mortality than any other CAs including NTDs. In addition, there was a reduction in risk for imperforate anus after the periconceptional folic acid $(0.4$ $\mathrm{mg}$ ) supplementation in China [12]. Some reduction was found in the occurrence of nonsyndromic omphalocele in a US population-based case-control study [13]. These CAs are considered as candidate $C A s$ for the primary prevention by folic acid containing multivitamins or folic acid alone. An excellent review paper about multivitamin supplementation and risk for CAs other than NTDs was published in 2004 [6].

Recently there have been two main debated questions regarding the primary prevention of CAs. The first question is whether the use of folic acid alone or folic acid-containing multivitamins is better [14]. The second question is connected with the dilemma of whether the high dose of folic acid (5 mg) [15-16] might be better than a daily multivitamin with $0.4-0.8 \mathrm{mg}$ of folic acid. As far as I know the Hungarian data sets are unique to answer these questions. On the one hand now the results of the two Hungarian intervention trials are available and their pooled data are appropriate for the estimation of effectiveness of a folic acid $(0.8 \mathrm{mg})$ containing multivitamin supplementation during the periconceptional period for the primary prevention of NTD and other candidate CAs [14]. On the other hand the large population-based dataset of the Hungarian Case-Control Surveillance of Congenital Abnormalities (HCCSCA) [17] can provide a chance for the estimation of effectiveness of high dose of folic acid supplementation during the periconceptional period for the prevention of CAs.

Here I will summarize the methods and results of the two Hungarian intervention trials. In addition, I will describe the methods and the recent results of the HCCSCA from this aspect. 


\section{Materials and methods}

\section{a) Intervention trials}

The participants in the Hungarian periconceptional care program took part voluntarily in a randomized controlled trial (RCT) [2], and later in the two-cohort controlled trial (TCT) [7]. Participant women were periconceptionally supplemented with the same multivitamin (Table 1). Each supplemented woman was matched with a control pregnant woman who was not supplemented with multivitamin, folic acid or other micronutrients during the periconceptional period in the TCT, these women were selected from regional antenatal care clinics.

\section{b) The HCCSCA}

HCCSCA is based on the Hungarian Congenital Abnormality Registry (HCAR) [18] which is a national-based registry of cases with CAs. Notification of CAs is mandatory for physicians, and most are reported by obstetricians (in Hungary practically all deliveries occur in inpatient obstetric clinics) and pediatricians (who are working in the neonatal units of inpatient obstetric clinics and various inpatient and outpatient pediatric clinics). Autopsy was mandatory for all infant deaths and usual in stillborn fetuses during the study period. Pathologists sent a copy of the autopsy report to the HCAR if defects were identified in stillbirths and infant deaths. Since 1984 reported fetal defects from antenatal diagnostic centers have also been included to the HCAR. Thus, the recorded total prevalence of cases with CA was 35 per 1000 informative offspring (liveborn infants, stillborn fetuses and electively terminated malformed fetuses) and about $90 \%$ of major CAs were reported to the HCAR during the 17 years of the study period between 1980 and 1996. Cases with isolated minor anomalies (or variants) such as umbilical hernia, hydrocele, simian crease, etc. were excluded from the data set of the HCAR.

The HCCSCA procedure included five steps:

The first step was the identification of cases from the data set of the HCAR that were reported in the first 3 months after births or termination of pregnancies. These cases comprised $77 \%$ of the HCAR [17]. Cases of isolated CAs and multiple CAs were included in the data set of the HCCSCA. However, three mild CAs (such as congenital dislocation of the hip based on the Ortolani click, congenital inguinal hernia, and hemangiomas), and CA-syndromes of Mendelian and chromosomal origin were excluded.

The second step was to ascertain appropriate controls from the National Birth Registry of the Central Statistical Office. In general, two newborn infants without CAs were matched to every case according to sex, birth week and district of parents' residence after 2 months of case notification. (Three newborn infants were selected for each case between 1986 and 1992.)

The third step was to obtain exposure data from three sources. (i) A post-paid questionnaire with an explanatory letter and a list of medicines (drugs and pregnancy supplements) and diseases was mailed immediately after the selection of cases and controls. The questionnaire requested information on, among others, medicine intakes, pregnancy complications, and maternal diseases during pregnancy according to gestational month, and any family history of CAs. In order to standardize the answers, mothers were asked to read the enclosed lists of medicines and diseases as a memory aid before they replied. The mean \pm SD time elapsed between the birth or pregnancy termination and return of the questionnaire was $3.5 \pm 1.2$ and $5.2 \pm 2.9$ months in the case and control groups, respectively. (ii) Furthermore, mothers were requested to send us the antenatal care logbook and every medical record concerning their diseases during pregnancy and their child's CA. Obstetricians in antenatal care are obliged to record all prescribed medicines for women regarding pregnancy, pregnancy-related complications and diseases in the logbook. Data from the antenatal care logbook were available in $88.4 \%$ of cases and in $93.8 \%$ of controls. (iii) Regional district nurses were asked to visit and to question all case families and 200 control families who did not respond. Overall, information was available on $96.3 \%$ of cases who could be located ( $84.4 \%$ from reply, $11.9 \%$ from visit), and $83.1 \%$ of controls who could be located and from information was sought ( $82.6 \%$ from reply, $0.5 \%$ from visit). The ethics committee considered this follow-up to be disturbing for the parents of all healthy control children [19].

The fourth step was the evaluation of folic acid intake from seven different aspects: 
1. The source of information. Three groups were differentiated: (i) data only from the antenatal care logbook and/or other medical records; (ii) data only from the questionnaire; and (iii) concordant data from both the medical records and the questionnaire.

2. The type of treatment. Two groups were differentiated in the analysis: folic acid alone and folic acid plus other medicines.

3. The route of administration. Only tablet for oral use was marketing.

4. The dose. In Hungary, folic acid was available as a $3 \mathrm{mg}$ tablet.

5. The duration of treatment.

6. The gestational age. This was calculated from the first day of last menstrual period. Three time intervals were considered: (i) The first month of pregnancy, as an indicator of preconceptional use of folic acid. The first two weeks are before conception, and the second two weeks comprise the preimplantation and implantation periods. (ii) The second month of gestation, including from the first day of the third week until the last day of the sixth week of fetal development (but from the fifth week until the eight week of gestational age) and it overlaps with the so-called critical period of some major CAs, such as NTDs and cleft lip \pm cleft palate or it precedes the critical period of other CAs, e.g. posterior cleft palate and hypospadias. (iii) The third through ninth months of gestation.

7. Potential confounding factors. Maternal age, birth order, marital and employment status, maternal disorders and other medicine (drug and pregnancy supplement) uses were evaluated.

The fifth step was the statistical analysis of data using the SAS version 8.02 statistical software package (SAS Institute Ins., Cary, NC, USA). Potential confounders were evaluated using Student's ttest for quantitative variables and odds ratios (ORs) with $95 \%$ confidence interval (CI) for categorical variables between the supplemented and unsupplemented groups. The occurrence of folic acid supplementation in the total control group was compared with the frequency of this supplementation in 25 CA-groups during the first and second month of gestation and adjusted odds ratios (ORs) with 95\% confidence interval (CI) for potential confounders were evaluated in an ordinary logistic regression model.

The data set of the HCCSCA between 1980 and 1996 is evaluated here because the method of data collection was changed after 1996.

\section{Results}

\section{a) Intervention trials}

The results of these two intervention trials with regard to the primary prevention of NTDs are shown in Table 2. The pooled findings of these trials indicate that approximately $92 \%$ of NTDs may be prevented using a micronutrient ("multivitamin") combination containing a physiological dose (0.8 $\mathrm{mg})$ of folic acid during the periconceptional period.

Another important finding of the RCT was a significant reduction in the total (birth + fetal) prevalence of CAs (20.64/1,000 in the supplemented group compared with 40.57/1,000 in the unsupplemented group (i.e. OR: 0.53 with $95 \% \mathrm{CI}: 0.35,0.70$ ) and this cannot be explained by the reduction of NTD offspring. The total reduction in CAs without NTD cases was 19.93/1,000 which exceeded the total prevalence of NTD $(2.78 / 1,000)$ in Hungary by 7.2 fold. Isolated CAs of the urinary tract and cardiovascular system also showed a significant decrease while the occurrence of limb reduction CAs and congenital pyloric stenosis was somewhat but not significantly lower (Table 3).

The main goal of the TCT was to differentiate the chance and vitamin dependent effect of periconceptional multivitamin supplementation in the prevention of the above-mentioned candidate CAs and to identify preventable specific CA types within these CA groups (Table 3). The findings of the TCT partly confirmed the previous results of the RCT because a significant reduction was found in the group of cardiovascular CAs particularly for ventricular septal defects. The reduction in urinary tract CAs did not reach the level of significance but the obstructive CAs of the pelvicureteric junction showed a significant decrease in agreement with the findings of the RCT. The number of offspring was not enough to evaluate limb reduction CAs and congenital pyloric stenosis. Our results again did not show prevention for isolated orofacial clefts.

In conclusion, recent data provide encouragement for the concept that a considerable proportion of major CAs - beyond NTDs - are preventable by multivitamins containing low dose of folic acid.

\section{b) The HCCSCA}


The case group consisted of 22,843 malformed offspring. The prevalence of folic acid treatment during pregnancy was $49.4 \%$ in the case group (11,279 pregnant women). Of 38,151 controls, 20,775 (54.5\%) had mothers with folic acid supplementation.

The proportion of medically recorded folic acid use was $27.1 \%$ and $32.1 \%$ during the first month of gestation in the case and control groups, while these figures were $43.3 \%$ and $66.3 \%$ during the second month, respectively.

Of 22,843 cases, $1,733(15.4 \%)$ had mothers who used only folic acid during pregnancy, while this figure was 4,088 (19.7\%) among 38,151 controls.

The dose of folic acid was not reported or recorded in about $50 \%$ of pregnant women. In our validation study based on 600 pregnant women, $22.5 \%, 68.6 \%$ and $8.9 \%$ used $1(3 \mathrm{mg}), 2(6 \mathrm{mg})$ and 3 $(9 \mathrm{mg})$ tablets of folic acid, respectively.

Of 22,843 cases, 684 (3.0\%) had mothers with preconceptional folic acid supplementation, i.e. during the first month of gestation. Only $4(0.6 \%)$ did not continue the folic acid supplementation in the second month, while 464 (67.8\%) continued the use of folic acid until the end of pregnancy. Of 1,222 cases who had mothers with the onset of folic acid supplementation in the second month, 394 (32.2\%) did not continue it in the third month while 660 (54.0\%) continued folic acid use until the end of pregnancy. Of 38,151 controls, 1,526 (4.0\%) had mothers with preconceptional folic acid supplementation, $10(0.7 \%)$ stopped in the second month while $1,152(75.0 \%)$ continued folic acid supplementation until the end of pregnancy. Of 2,617 cases with mothers who started the use of folic acid in the second month of gestation, $636(24.3 \%)$ discontinued this supplementation after this month while $1,689(64.5 \%)$ continued it until the end of pregnancy.

Potential confounders of cases and controls in the total dataset and in mothers with preconceptional (first month of gestation) folic acid supplementation are shown in Table 4. Among maternal variables, the proportion of professional and managerial women was higher in the preconceptionally folic acid supplemented women particularly in the control group. There was no obvious difference in the prevalence of maternal diseases and drug uses between the two study groups.

Table 5 shows the effect of the high dose of folic acid supplementation in the first and the second month of gestation. The magnitude of prevention was estimated by the adjusted OR with $95 \%$ CI, all confounders were considered. All pregnant women who used folic acid during the second month irrespective of when they started in the second or in the first month of gestation but continued in the second month were included in this group. Three CA groups are differentiated at the evaluation of data.

The first group of CAs includes NTDs. There was a significant reduction in the total (birth+fetal) prevalence of these cases after the folic acid supplementation in the first month of gestation. Some but not significant decrease was seen after the use of folic acid supplementation in the second month. It is understandable because the critical period of NTDs covers the fifth and sixth weeks of gestation (i.e. the first part of the second month) and the protective effect of folic acid needs some time to achieve the necessary blood level.

Of 8 other "candidate" CAs, only two: posterior cleft palate and cardiovascular CAs had a reduction after the folic acid supplementation in the first month of gestation. The protective effect of folic acid supplementation in the second month of gestation was also found in two CA groups: cardiovascular CAs again and rectal/anal stenosis/atresia. In addition there was some reduction in the group of cleft lip \pm palate (OR:0.82), posterior cleft palate (OR:0.70) and obstructive urinary CAs (OR:0.70) with the upper limit of $95 \%$ CI near to 1 . Other candidate CAs such as limb reduction CAs, congenital pyloric stenosis and omphalocele did not show a reduction after the folic acid supplementation either in the first or in the second month of gestation. Though it is worth mentioning that the critical period of congenital pyloric stenosis is during the last trimester of pregnancy and the OR with $95 \%$ CI was 0.72, 0.52-1.00 after the folic acid supplementation during this period.

Third, our findings showed an unexpected reduction in some other CAs. The prevalence at birth of hypospadias was lower after the folic acid supplementation both in the first and second month of gestation. (A more limited reduction was found after the folic acid supplementation in the third month of gestation, adjusted OR with $95 \%$ CI was $0.89,0.81-0.99$. It is interesting because the critical period of hypospadias is prior to $14^{\text {th }}$ gestational week.) The prevalence at birth of poly/syndactyly was also reduced after the folic acid supplementation in the first month. The total (birth+fetal) prevalence of multiple CAs also decreased after the folic acid supplementation both in the first and second month of gestation. It is not shown in Table 4, but there was a reduction of microcephaly after the folic acid 
supplementation in the third month of gestation (OR with 95\% CI: 0.36, $0.18-0.75$ ). It is also interesting because the critical period of this CA is after the third month of gestation. Finally, it is important to note that the group of other CAs also showed a reduction both in the first and second month of gestation. However, 13 CA-groups were included in the other CA group and each of them did not show significant reduction separately.

Finally it is necessary to stress that there was a significant reduction after the high dose of folic acid supplementation in the first and second month of gestation in the total group of CAs. The level of this decrease was $24 \%$ and $21 \%$, respectively.

Table 6 demonstrates the comparison of preventive effectiveness of the folic acid $(0.8 \mathrm{mg})$ containing multivitamin in the pooled dataset of the two Hungarian intervention trials and the high dose of folic acid supplementation during the first and second month of gestation in the dataset of the HCCSCA. These findings will be discussed in the next section of the paper.

\section{Discussion}

The comparison of the results of the two Hungarian intervention trials and the HCCSCA provide an opportunity to estimate the preventive effectiveness of a folic acid (low dose: $0.8 \mathrm{mg}$ ) containing multivitamin and the high dose of folic acid alone for NTD and other CAs.

The multivitamin (Elevit pronatal ${ }^{\circledR}$ ) studied seems to be more effective for the reduction of NTD than high dose of folic acid. These findings are in agreement with the results of two recurrent NTD studies. Smithells et al. [20] used a multivitamin containing $0.36 \mathrm{mg}$ of folic acid and they were able to prevent $91 \%$ of recurrent NTD. The MRC Vitamin Study [1] used $4 \mathrm{mg}$ of folic acid and $71 \%$ of recurrent NTD were prevented. Thus the additive and/or synergestic effect of B vitamins such as folic acid, vitamins B2 [21], B6 [22] and B12 [23] can improve the preventive effectiveness of multivitamins. (The different possible preventive mechanisms of multivitamins and/or folic acid for NTD and other CAs [14] are not discussed here.) On the other hand, $0.4 \mathrm{mg}$ of folic acid was used in China as part of a public health campaign and the risk of NTD was reduced by $79 \%$ in areas with high rates of NTD (3.3 - 5.5 per 1,000) while the reduction was $49 \%$ in areas with low rates $(0.8-1.0$ per 1,000) [24]. Thus the gene-environmental interaction in the populations studied seems to be more important than the dose of folic acid.

Among candidate CAs, a reduction was found in the prevalence at birth of cardiovascular CAs both after the use of the multivitamin and the high dose of folic acid. However, the preventive effectiveness of the multivitamin was higher. A reduction in the occurrence of urinary tract CAs, congenital pyloric stenosis and limb reduction CAs was found only after the use of multivitamins in our intervention trials and other observational studies [6]. However, the multivitamin used in our intervention trials did not reduce the prevalence at birth of orofacial cleft, while the high dose of folic acid showed some preventive effect particularly for posterior cleft palate. Thus a dose dependent preventive effect of folic acid seems to be plausible [25]. Folic acid seems to be also effective for the prevention of rectal/anal stenosis/atresia. Omphalocele did not show any reduction after either multivitamin or folic acid supplementation in our data sets. (Unfortunately the differentiation of gastroschisis from omphalocele is not performed correctly in all cases of the HCCSCA).

Three CAs: hypospadias, poly/syndactyly and multiple CAs showed also reduction after the use of high dose of folic acid while a similar decrease was not found in their occurrence after the multivitamin use in the two intervention trials and in other observational studies [6]. Further studies are needed to differentiate the chance and vitamin-dependent causal effect in these CAs. It is important to stress that the group of other CAs including 13 CA-groups also showed a reduction, thus we can hope that some other CAs may have only a preventable fraction by folic acid.

For all CAs the risk reduction associated with periconceptional multivitamin supplementation was $47 \%$ in the Hungarian RCT [2-5] while it was only $26 \%$ in the Hungarian TCT [7] though the same multivitamin was used. However, the predominance of participants were primiparous at low risk in the Hungarian RCT while the major part of participants had a high risk in the Hungarian TCT (see Table 1). About 20\% risk reduction was found in the Atlanta case-control study after periconceptional multivitamin use [6]. The results of our recent Hungarian case-control study showed a $24 \%$ reduction for all CAs after the periconceptional use of high dose of folic acid.

Of course, the valid results of studies are determined by the quality of study design and experts. The RCT had only one problem and it was the limited statistical power due to the number of subjects. 
The TCT was complicated by the unexpected high participation of pregnant women at high risk. Here the strengths and weaknesses of the HCCSCA are summarized.

The strengths of the HCCSCA are as follows:

1. Large and population-based data set, including 30,054 pregnant women who received folic acid supplementation in a racially homogeneous European-Caucasian population.

2. Matching of cases with controls.

3. Good compliance by the mothers in responding to the questionnaire.

4.Availability of prospective and medically recorded data in folic acid supplementation in a certain portion of the study groups.

5. Knowledge of exposure time, i.e. folic acid supplementation.

6. Knowledge of confounders.

7. A high validity in the diagnosis of CAs.

However, this data set also has some limitations:

1. The response rate was $84 \%$ for cases, and $83 \%$ for controls; however, there was an active follow-up for all mothers in the case group who did not respond to the questionnaire, but only 200 population control mothers with no response were visited at home. However, the prevalence of folic acid supplementation did not differ significantly between the respondents and the nonrespondent controls [19].

2. Most folic acid uses were based on information that was collected retrospectively from mothers. One explanation might be that folic acid was prescribed by other physicians independently of antenatal care. In addition a smaller proportion of cases than controls had medically recorded exposure [26], but the information of mothers is valid.

3. The absolute number of women taking folic acid in the first month of gestation was small, which limited the statistical power.

4. Most women with folic acid supplementation were treated with other drugs and a small portion with multivitamins as well. However, their proportion was similar in the two study groups and other medicine uses were considered as a confounder.

5. There is an underascertainment of medicine use during pregnancy [19].

The major methodological problem is the comparability of results derived from intervention trials and CA-surveillance because the data of the latter depends on the responsibility and expertise of hundred of medical doctors. This dilemma explains that our comparative findings can only be considered as crude estimates. Nevertheless, our study is the first in the international literature which compare the preventive effectiveness of the multivitamin studied and high dose of folic acid in the same population.

In conclusion, findings are consistent that periconceptional multivitamin and folic acid supplementation reduce the overall occurrence of CAs, in addition to the demonstrated effect on NTD. At present we can identify some other specific CAs which seem to be appropriate for the primary prevention by multivitamins or folic acid, though further studies are needed to determine the optimal method and the possible risk reduction. However, any risk reduction of specific and overall CAs is important from public health aspect. At present we can recommend the daily use of multivitamin supplement including $0.4-0.8 \mathrm{mg}$ of folic acid with a healthy diet and lifestyle for women who want to do their best to have a baby without NTD and some other CAs.

\section{Conflict of interest}

The author has declared that no conflict of interest exists.

\section{References}

1. MRC Vitamin Study Research Group. Prevention of neural tube defects: results of the Medical Research Council vitamin study. Lancet 1991; 338: 131-137.

2. Czeizel AE, Dudás I. Prevention of the first occurrence of neural-tube defects by periconceptional vitamin supplementation. N Engl J Med 1992; 327: 1832-1835.

3. Czeizel AE. Prevention of congenital abnormalities by periconceptional multivitamin supplementation. Brit Med J 1993; 306: 1645-1648.

4. Czeizel AE. Reduction of urinary tract and cardiovascular defects by periconceptional multivitamin supplementation. Am J Med Genet 1996; 62: 179-183. 
5. Czeizel AE. Periconceptional folic acid-containing multivitamin supplementation. Eur J Obstet Gynec Reprod Biol 1998; 75: 151-161.

6. Botto LD, Olney RS, Erickson JD. Vitamin supplements and the risk for congenital anomalies other than neural-tube defects. Am J Med Genet 2004; 1250: 12-21.

7. Czeizel AE, Dobó M, Vargha P. Hungarian intervention two-cohort controlled trial of periconceptional multivitamin supplementation to prevent certain congenital abnormalities: Birth Defects Research Part B. Developmental and Reproductive Toxicology, submitted.

8. Mulinare J, Erickson JD, James LM, Berry RJ. Does periconceptional use of multivitamins reduce the occurrence of birth defects? Am J Epidemiol 1995; 141: 53.

9. Tolarova M. Periconceptional supplementation with vitamins and folic acid to prevent recurrence of cleft lip. Lancet 1982; 2: 217.

10. Hayes C, Werler MM, Willett WC, Mitchell AA. Case-control study of periconceptional folic acid supplementation and oral clefts. Am J Epidemiol 1996; 143: 1229-1234.

11. Werler MM, Hayes C, Louik C. Multivitamin use and risk of birth defects. Am J Epidemiol 1999; 150: 675682.

12. Myers MF, Li S, Correa-Villasenon A et al. Folic acid supplementation and risk for imperforate anus in China. Am J Epidemiol 2001; 154: 1051-1056.

13. Botto LD, Mulinare J, Erickson JD. Occurrence of omphalocele in relation to maternal multivitamin use: A population-based study. Pediatrics 2002; 109: 904-908.

14. Czeizel AE. Reducing risk of birth defects with periconceptional micronutrient supplementation. In: Delange FM, West KPJr, eds. Micronutrient Deficiencies in the First Months of Life- Nestle Nutrition Workshop Series Pediatric Program. Basel.:Verey/S. Karger AG. 2003: 309-325.

15. Wald NJ, Law MR, Morris JK, Wald DS. Quantifying the effects of folic acid. Lancet 2001; 358: $2069-2073$.

16. Wald NJ. Folic acid and the prevention of neural-tube defects. Lancet 2004; 350: 101-103.

17. Czeizel AE, Rockenbauer M, Siffel Cs, Varga E. Description and mission evaluation of the Hungarian CaseControl Surveillance of Congenital Abnormalities, 1980-1996. Teratology 2001; 63: 176-185.

18. Czeizel AE. The first 25 years of the Hungarian Congenital Abnormality Registry. Teratology 1997; 55: 299305.

19. Czeizel AE, Petik D, Vargha P. Validation studies of drug exposures in pregnant women. Pharmacoepid Drug Safety 2003; 12: 409-416.

20. Smithells RW, Sheppard S, Wild J, Schorah CJ. Prevention of neural tube defect recurrences in Yorkshire: final report. Lancet 1989; 2: 498-499.

21. McNulty H, McKinely MC, Wilson B et al. Impaired functioning of thermolabile methylenetetrahydrofolate reductase is dependent on riboflavin status: Implications for riboflavin requirements. Am J Clin Nutr 2002; 76: 436-441.

22. Jacques PF, Boston AG, Wilson PWT et al. Determinants of plasma total homocysteine concentration in the Framingham Offspring cohort. Am J Clin Nutr 2001; 73: 613-621.

23. Kirke PN, Molloy AM, Daly LE, et al. Maternal plasma folate and vitamin B12 are independent risk factors for neural tube defects. Q J Med 1993; 86: 703-708.

24. Berry RJ, Li Z, Erickson JD et al. Prevention of neural-tube defects with folic acid in China. China-US Collaborative Project for Neural Tube Defect Prevention. N Engl J Med 1999; 341: 1485-1490.

25. Czeizel AE, Tímár L, Sárközi A. Dose-dependent effect of folic acid on the prevention of orofacial clefts. Pediatrics 1999; 104: e66.

26. Rockenbauer M, Olsen J, Czeizel AE, Pedersen L, Sorensen HT and EuroMAP group. Recall bias in a casecontrol study on the use of medicine during pregnancy. Epidemiology 2001; 12: 461-466. 


\section{Tables}

Table 1. Study design and characteristics of the two Hungarian intervention trials

\begin{tabular}{|c|c|c|}
\hline Study design & Randomised controlled trial & Two-cohort controlled trial \\
\hline Study medicine & $\begin{array}{c}\text { Elevit prenatal } \\
\text { (containing } 0.8 \text { mg of folic acid, } \\
\text { vitamins B2, B6 and B12) }\end{array}$ & $\begin{array}{c}\text { Elevit prenatal } \\
\text { (containing } 0.8 \mathrm{mg} \text { of folic acid, } \\
\text { vitamins } \mathrm{B} 2, \mathrm{~B} 6 \text { and } \mathrm{B} 12 \text { ) }\end{array}$ \\
\hline Duration of treatment & $\begin{array}{c}\text { Periconceptional } \\
\text { (one month before, three months } \\
\text { after conception) }\end{array}$ & $\begin{array}{l}\text { Periconceptional } \\
\text { (one month before, three months } \\
\text { after conception) }\end{array}$ \\
\hline $\begin{array}{l}\text { Recruitment of supplemented } \\
\text { participants }\end{array}$ & $\begin{array}{l}\text { Periconceptional care } \\
\text { (coordinating center in } \\
\text { Budapest) }\end{array}$ & $\begin{array}{l}\text { Periconceptional care } \\
\text { (all centers in Hungary) }\end{array}$ \\
\hline $\begin{array}{l}\text { Number of supplemented } \\
\text { participants }\end{array}$ & 2,819 (confirmed pregnancy) & 3,069 (at $14^{\text {th }}$ week of gestation) \\
\hline $\begin{array}{l}\text { Recruitment of unsupplemented } \\
\text { participants }\end{array}$ & $\begin{array}{c}\text { Periconceptional care } \\
\text { (coordinating center in } \\
\text { Budapest) }\end{array}$ & $\begin{array}{l}\text { Regional antenatal care } \\
\text { (all clinics in Hungary) }\end{array}$ \\
\hline $\begin{array}{l}\text { Number of unsupplemented } \\
\text { participants }\end{array}$ & 2,683 (confirmed pregnancy) & 3,069 (at $14^{\text {th }}$ week of gestation) \\
\hline $\begin{array}{l}\text { Selection or matching criteria of } \\
\text { supplemented and } \\
\text { unsupplemented women }\end{array}$ & Randomization & $\begin{array}{l}\text { Age, socioeconomic status, } \\
\text { region }\end{array}$ \\
\hline Characteristics of participants & Predominance of primiparous & $\begin{array}{l}\text { Predominance of pregnant } \\
\text { women at high risk }\end{array}$ \\
\hline $\begin{array}{l}\text { Primary endpoints } \\
\text { (No.) }\end{array}$ & $\begin{array}{c}\text { Informative offspring } \\
(2,471 \text { vs } 2,391)\end{array}$ & $\begin{array}{c}\text { Informative offspring } \\
\text { (3,056 vs } 3,056)\end{array}$ \\
\hline Study period & $\begin{array}{c}\text { February 1, } 1984-\text { April 30, } \\
1991\end{array}$ & May 1, 1993 - April 30, 1996 \\
\hline $\begin{array}{ll}\begin{array}{l}\text { Evaluation } \\
\text { outcomes }\end{array} & \text { of pregnancy } \\
\end{array}$ & April 30, 1992 & April 30, 1997 \\
\hline End of follow-up & April 30, 1993 & April 30, 1993 \\
\hline
\end{tabular}

Table 2 Total (birth + fetal) prevalence of neural-tube defects (NTDs) in informative offspring of women taking folic acid-containing multivitamin supplement and no (multivitamin or folic acid) supplement during periconceptional period in the two Hungarian intervention trials.

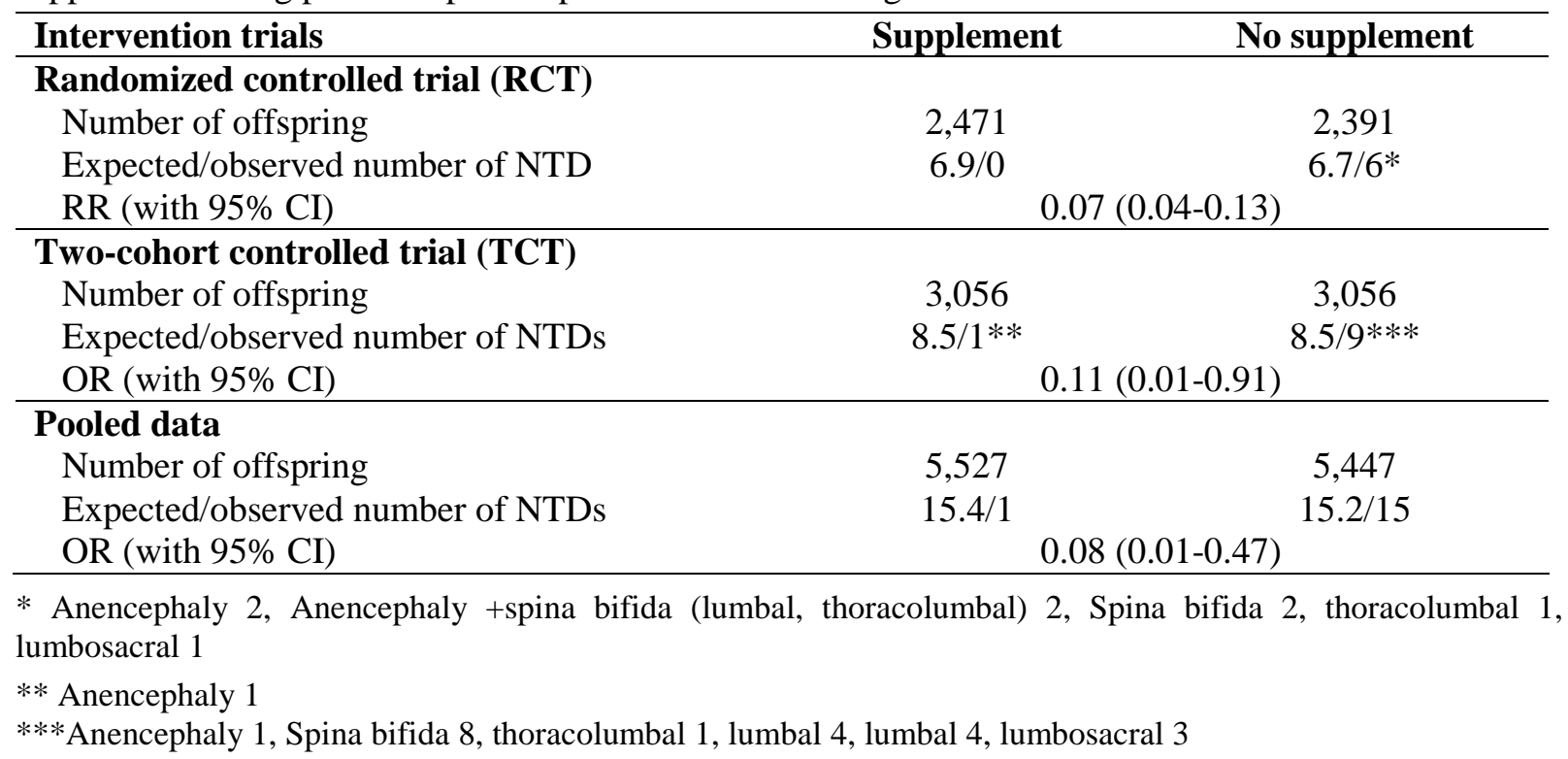


Table 3. The efficacy of periconceptional folic acid-containing multivitamin supplementation in the primary prevention of some major CA-groups in the two Hungarian intervention trials

\begin{tabular}{|c|c|c|c|c|c|c|}
\hline \multirow[t]{3}{*}{ Isolated CA groups } & \multicolumn{4}{|c|}{ Hungarian intervention trials } & \multirow{2}{*}{\multicolumn{2}{|c|}{ Pooled data }} \\
\hline & \multicolumn{2}{|c|}{ RCT } & \multicolumn{2}{|c|}{ TCT } & & \\
\hline & $\begin{array}{c}\text { No } \\
\text { supplement } \\
(\mathrm{n}=2,391)\end{array}$ & $\begin{array}{c}\text { Supple- } \\
\text { ment } \\
(\mathrm{n}=2,471)\end{array}$ & $\begin{array}{c}\text { No } \\
\text { supplement } \\
(\mathrm{n}=3,056)\end{array}$ & $\begin{array}{l}\text { Supplement } \\
(\mathrm{n}=3,056)\end{array}$ & $\begin{array}{c}\text { No } \\
\text { supplement } \\
(\mathrm{n}=5,447)\end{array}$ & $\begin{array}{c}\text { Supple- } \\
\text { ment } \\
(\mathrm{n}=5,527)\end{array}$ \\
\hline \multicolumn{7}{|l|}{ Urinary tract CAs } \\
\hline \multicolumn{7}{|l|}{ Obstructive CAs } \\
\hline $\begin{array}{l}\text { Pelvicureteric } \\
\text { junction }\end{array}$ & 4 & 0 & 13 & 2 & 17 & 2 \\
\hline Other locations & 1 & 1 & 6 & 8 & 7 & 9 \\
\hline Renal a/dysgenesis & 3 & 0 & 0 & 2 & 3 & 2 \\
\hline Cystic kidney & 1 & 1 & 0 & 2 & 1 & 3 \\
\hline Total & 9 & 2 & 19 & 14 & 28 & 16 \\
\hline OR $(95 \% \mathrm{CI})$ & \multicolumn{2}{|c|}{$0.21(0.05,0.95)$} & \multicolumn{2}{|c|}{$0.71(0.33,1.50)$} & \multicolumn{2}{|c|}{$0.56(0.30,1.04)$} \\
\hline \multicolumn{7}{|l|}{ Cardiovascular CAs } \\
\hline \multicolumn{7}{|l|}{ Conotruncal } \\
\hline $\begin{array}{l}\text { Ventricular septal } \\
\text { defect }\end{array}$ & 8 & 2 & 19 & 5 & 27 & 7 \\
\hline Others & 2 & 1 & 1 & 3 & 3 & 4 \\
\hline Subtotal & 10 & 3 & 20 & 8 & 30 & 11 \\
\hline Others & 10 & 7 & 30 & 23 & 40 & 30 \\
\hline Total & 20 & 10 & 50 & 31 & 70 & 41 \\
\hline OR $(95 \% \mathrm{CI})$ & \multicolumn{2}{|c|}{$0.42(0.19,0.98)$} & \multicolumn{2}{|c|}{$0.60(0.38,0.96)$} & \multicolumn{2}{|c|}{$0.57(0.39,0.85)$} \\
\hline \multicolumn{7}{|l|}{ Limb reduction CAs } \\
\hline Terminal transverse & 2 & 1 & 3 & 1 & 5 & 2 \\
\hline Others & 3 & 0 & 0 & 0 & 3 & 0 \\
\hline Total & 5 & 1 & 3 & 1 & 8 & 2 \\
\hline OR $(95 \% \mathrm{CI})$ & \multicolumn{2}{|c|}{$0.19(0.03,1.18)$} & \multicolumn{2}{|c|}{$0.33(0.01,3.71)$} & \multicolumn{2}{|c|}{$0.25(0.05,1.16)$} \\
\hline $\begin{array}{l}\text { Congenital pyloric } \\
\text { stenosis }\end{array}$ & 8 & 2 & 2 & 0 & 10 & 2 \\
\hline OR $(95 \% \mathrm{CI})$ & $0.24(0.0$ & , 1.14) & $0.00(0$ & $0,26.8)$ & $0.20(0.0$ & , 0.90) \\
\hline \multicolumn{7}{|l|}{ Orofacial clefts } \\
\hline Cleft lip \pm palate & 3 & 4 & 2 & 3 & 5 & 7 \\
\hline $\begin{array}{l}\text { Posterior cleft } \\
\text { palate }\end{array}$ & 2 & 0 & 1 & 1 & 3 & 1 \\
\hline Total & 5 & 4 & 3 & 4 & 8 & 8 \\
\hline OR $(95 \% \mathrm{CI})$ & \multicolumn{2}{|c|}{$0.77(0.22,2.69)$} & \multicolumn{2}{|c|}{$1.63(0.31,2.88)$} & \multicolumn{2}{|c|}{$0.99(0.37,2.63)$} \\
\hline
\end{tabular}


Table 4. Basic characteristics of cases and controls in the total datasets and in mothers who used folic acid in the first month of pregnancy, i.e. preconceptionally

\begin{tabular}{|c|c|c|c|c|c|c|c|c|}
\hline & \multicolumn{4}{|c|}{ Cases } & \multicolumn{4}{|c|}{ Controls } \\
\hline & \multicolumn{2}{|c|}{$\begin{array}{c}\text { Total } \\
\text { dataset } \\
(\mathbf{N}=\mathbf{2 2 , 8 4 3 )}\end{array}$} & \multicolumn{2}{|c|}{$\begin{array}{l}\text { Folic acid use } \\
\text { in the } \\
\text { first month } \\
(\mathrm{N}=684)\end{array}$} & \multicolumn{2}{|c|}{$\begin{array}{c}\text { Total } \\
\text { dataset } \\
(\mathbf{N}=38,151)\end{array}$} & \multicolumn{2}{|c|}{$\begin{array}{l}\text { Folic acid use } \\
\text { in the } \\
\text { first month } \\
(\mathrm{N}=\mathbf{1 , 5 2 6}) \\
\end{array}$} \\
\hline & $\mathbf{N}$ & $\%$ & $\mathbf{N}$ & $\%$ & $\mathbf{N}$ & $\%$ & $\mathbf{N}$ & $\%$ \\
\hline \multicolumn{9}{|l|}{ Maternal age (yr) } \\
\hline$<25$ & 10,945 & 47.9 & 327 & 47.8 & 17,994 & 47.2 & 746 & 48.9 \\
\hline $25-29$ & 7,154 & 31.3 & 236 & 34.5 & 12,885 & 33.8 & 513 & 33.6 \\
\hline$>29$ & 4,744 & 20.8 & 121 & 17.7 & 7,272 & 19.1 & 267 & 17.5 \\
\hline Mean ( \pm S.D.) & \multicolumn{2}{|c|}{$25.4(5.3)$} & \multicolumn{2}{|c|}{$25.2(4.9)$} & \multicolumn{2}{|c|}{$25.4(4.9)$} & \multicolumn{2}{|c|}{$25.3(4.8)$} \\
\hline \multicolumn{9}{|l|}{ Birth order } \\
\hline 1 & 1,299 & 62.3 & 429 & 62.7 & 24,184 & 63.4 & 949 & 62.2 \\
\hline$\geq 2$ & 8,614 & 37.7 & 255 & 37.3 & 13,967 & 36.6 & 577 & 37.8 \\
\hline Mean ( \pm S.D.) & \multicolumn{2}{|c|}{$1.9(1.1)$} & \multicolumn{2}{|c|}{$1.8(1.1)$} & \multicolumn{2}{|c|}{$1.7(0.9)$} & \multicolumn{2}{|c|}{$1.7(0.9)$} \\
\hline Unmarried & 1,040 & 4.5 & 28 & 4.1 & 1,217 & 3.2 & 34 & 2.2 \\
\hline \multicolumn{9}{|l|}{ Employment status } \\
\hline Professional & 1,091 & 8.3 & 74 & 10.8 & 4,353 & 11.4 & 202 & 13.2 \\
\hline Managerial & 4,968 & 21.7 & 191 & 27.9 & 10,134 & 26.6 & 479 & 31.4 \\
\hline Skilled worker & 6,329 & 27.7 & 199 & 29.1 & 11,690 & 30.6 & 429 & 28.1 \\
\hline Semiskilled worker & 3,869 & 16.9 & 106 & 15.5 & 5,783 & 15.2 & 203 & 13.3 \\
\hline Unskilled worker & 1,503 & 6.6 & 34 & 5.0 & 1,859 & 4.9 & 61 & 4.0 \\
\hline Housewife & 2,128 & 9.3 & 36 & 5.3 & 2,038 & 5.3 & 58 & 3.8 \\
\hline Others & 2,145 & 9.4 & 44 & 6.4 & 2,294 & 6.0 & 94 & 6.2 \\
\hline \multicolumn{9}{|l|}{ Pregnancy supplements } \\
\hline $\begin{array}{l}\text { Multivitamins in the } \\
\text { first gestational month }\end{array}$ & 1,330 & 5.8 & 45 & 3.4 & 2,509 & 6.9 & 110 & 4.4 \\
\hline
\end{tabular}


Table 5. The dataset of the HCCSCA, 1980-1996 regarding high dose of folic acid supplementation in the first and second month of gestation.

\begin{tabular}{|c|c|c|c|c|c|c|c|c|c|}
\hline & \multirow{2}{*}{$\begin{array}{c}\text { Grand } \\
\text { total } \\
\text { No. }\end{array}$} & \multicolumn{2}{|c|}{ First month } & \multirow[t]{2}{*}{ POR } & \multirow[t]{2}{*}{ 95\% CI } & \multicolumn{2}{|c|}{$\begin{array}{c}\text { Second } \\
\text { month }\end{array}$} & \multirow[t]{2}{*}{ POR } & \multirow[t]{2}{*}{$95 \%$} \\
\hline & & No. & $\%$ & & & No. & $\%$ & & \\
\hline Total controls & 38,151 & 1,526 & 4.0 & \multicolumn{2}{|r|}{ referent } & 2,617 & 6.9 & \multicolumn{2}{|c|}{ referent } \\
\hline Neural-tube defects & 1,202 & 32 & 2.7 & 0.68 & $0.47-0.97$ & 66 & 5.5 & 0.80 & $0.62-1.03$ \\
\hline Candi & & & & & & & & & \\
\hline Cleft lip \pm palate & 1,374 & 48 & 3.5 & 0.89 & $0.67-1.20$ & 76 & 5.5 & 0.82 & $0.64-1.03$ \\
\hline $\begin{array}{l}\text { Posterior cleft } \\
\text { palate }\end{array}$ & 601 & 12 & 2.0 & 0.50 & $0.28-0.89$ & 29 & 4.8 & 0.70 & $0.48-1.02$ \\
\hline Cardiovascular CAs & 4,479 & 142 & 3.2 & 0.81 & $0.68-0$ & 227 & 5.1 & 0.75 & $0.65-0.86$ \\
\hline $\begin{array}{l}\text { Rect } \\
\text { atresia/s }\end{array}$ & 220 & 4 & 1.8 & 0.46 & $0.17-$ & 6 & 2.7 & 0.39 & $0.17-0.88$ \\
\hline $\begin{array}{l}\text { Obstructive urinary } \\
\text { As }\end{array}$ & 502 & 13 & 2.6 & 0.64 & $0.37-1.12$ & 24 & 4.8 & 0.70 & $0.46-1.06$ \\
\hline Limb reduction CAs & 548 & 15 & 2.7 & 0.69 & $0.41-$ & 33 & 6.0 & 0.89 & $0.62-1.26$ \\
\hline Congenital pyloric & 241 & 11 & 4.6 & 1.16 & 0.63 & 11 & 4.6 & 0.65 & $0.35-1.19$ \\
\hline steno & & & & & & & & & \\
\hline Omphal & 238 & 10 & 4.2 & 1.07 & $0.57-2.02$ & 10 & 4.2 & 0.60 & $0.32-1.13$ \\
\hline New c & & & & & & & & & \\
\hline & 038 & 83 & 2.7 & 0.68 & & 163 & 5.4 & 0.78 & $0.66-0.92$ \\
\hline idactyly & 1,744 & 43 & 2.5 & 0.62 & $0.45-0$ & 104 & 6.0 & 0.88 & $0.72-1.08$ \\
\hline Multiple CAs & 1,349 & 34 & 2.5 & 0.64 & $0.45-0$ & 69 & 5.1 & 0.75 & $0.59-0.96$ \\
\hline Others & 7,307 & 237 & 3.2 & $\mathbf{0 . 8 0}$ & $0.70-0.92$ & 403 & 5.5 & 0.79 & $0.71-0.88$ \\
\hline Total & 22,843 & 684 & 3.0 & 0.76 & $0.70-0.84$ & 1,221 & 5.3 & 0.79 & $0.73-0.84$ \\
\hline
\end{tabular}

Table 6. Comparison of preventive effectiveness of the folic acid $(0.8 \mathrm{mg})$ containing multivitamin $\left(\right.$ Elevit prenatal ${ }^{\circledR}$ ) in the pooled dataset of the two Hungarian intervention trials and the high dose (in general $6 \mathrm{mg}$ ) of folic acid supplementation during the first and second month of gestation in the dataset of the HCCSCA.

\begin{tabular}{|c|c|c|c|c|c|c|}
\hline \multirow[t]{3}{*}{ CA groups } & \multicolumn{2}{|c|}{$\begin{array}{l}\text { Intervention trials } \\
\text { (multivitamin) }\end{array}$} & \multicolumn{4}{|c|}{ HCCSCA (folic acid) } \\
\hline & \multirow[b]{2}{*}{ OR } & \multirow[b]{2}{*}{$95 \% \mathrm{CI}$} & \multicolumn{2}{|c|}{ First month } & \multicolumn{2}{|c|}{ Second month } \\
\hline & & & OR & $95 \% \mathrm{CI}$ & OR & $95 \% \mathrm{CI}$ \\
\hline Neural-tube defects & 0.08 & $0.01-0.47$ & 0.68 & $0.47-0.97$ & 0.80 & $0.62-1.03$ \\
\hline \multicolumn{7}{|l|}{ Candidate CAs } \\
\hline Cleft lip \pm palate & 1.42 & $0.42-4.43$ & 0.89 & $0.67-1.20$ & 0.82 & $0.64-1.03$ \\
\hline Posterior cleft palate & 0.34 & $0.00-3.23$ & 0.50 & $0.28-0.89$ & 0.70 & $0.48-1.02$ \\
\hline Cardiovascular CAs* & 0.57 & $0.39-0.85$ & 0.81 & $0.68-0.96$ & 0.75 & $0.65-0.86$ \\
\hline $\begin{array}{ll}\text { Congenital pyloric } \\
\text { stenosis* }\end{array}$ & 0.20 & $0.04-0.90$ & 1.16 & $0.63-2.13$ & 0.65 & $0.35-1.19$ \\
\hline $\begin{array}{c}\text { Rectal/anal } \\
\text { atresia/stenosis }\end{array}$ & 0.20 & $0.02-1.69$ & 0.46 & $0.17-1.23$ & 0.39 & $0.17-0.88$ \\
\hline $\begin{array}{l}\text { Obstructive urinary } \\
\text { CAs }\end{array}$ & 0.19 & $0.04-0.86$ & 0.64 & $0.37-1.12$ & 0.70 & $0.46-1.06$ \\
\hline Limb reduction CAs & 0.25 & $0.05-1.16$ & 0.69 & $0.41-1.16$ & 0.89 & $0.62-1.26$ \\
\hline Omphalocele & 2.01 & $0.44-10.81$ & 1.07 & $0.57-2.02$ & 0.60 & $0.32-1.13$ \\
\hline \multicolumn{7}{|l|}{ New candidate CAs } \\
\hline Hypospadias & 0.62 & $0.32-1.53$ & 0.68 & $0.55-0.86$ & 0.78 & $0.66-0.92$ \\
\hline Poly/syndactyly & 0.73 & $0.24-2.31$ & 0.62 & $0.45-0.84$ & 0.88 & $0.72-1.08$ \\
\hline Multiple CAs & 0.89 & $0.47-1.68$ & 0.64 & $0.45-0.90$ & 0.75 & $0.59-0.96$ \\
\hline
\end{tabular}

